\section{Mucopolissacaridose em um cão: relato de caso}

\author{
Mucopolysaccharidosis in a dog: a case report
}

\begin{abstract}
Cristiano Chaves Pessoa Veiga', Laura Iglesias de Oliveira², Ricardo Siqueira da Silva ${ }^{3}$, Mariana Correia Oliveira ${ }^{4}$ Yasmin Daoualibi ${ }^{5}$, Eveliny Oliveira Deleutério ${ }^{4}$, Luciano da Silva Alonso ${ }^{6}$ \& Marilene de Farias Brito ${ }^{7 *}$

'Médico veterinário. Setor de Diagnóstico por Imagem, Hospital Veterinário de Pequenos Animais, Universidade Federal Rural do Rio de Janeiro - UFRRJ, Seropédica, RJ, Brasil

${ }^{2}$ Médica veterinária, Professora de Anatomia Patológica Veterinária. Universidade Severiano Sombra - USS, Vassouras, RJ, Brasil ${ }^{3}$ Professor. Departamento de Clínica e Patologia Cirúrgica, Instituto de Veterinária, Universidade Federal Rural do Rio de Janeiro - UFRRJ, Seropédica, RJ, Brasil

${ }^{4}$ Doutorandas. Programa de Pós-graduação em Medicina Veterinária (Patologia e Ciências Clínicas) - PPGMV, Universidade Federal Rural do Rio de Janeiro - UFRRJ, Seropédica, RJ, Brasil

${ }^{5}$ Médica veterinária, Residente. Setor de Patologia Animal, Universidade Federal Rural do Rio de Janeiro - UFRRJ, Seropédica, RJ, Brasil

'Professor. Departamento de Anatomia Animal e Humana, Universidade Federal Rural do Rio de Janeiro - UFRRJ, Seropédica, RJ, Brasil

7Professora. Departamento de Epidemiologia e Saúde Pública - DESP, Universidade Federal Rural do Rio de Janeiro - UFRRJ, Seropédica, RJ, Brasil
\end{abstract}

\section{Resumo}

A Mucopolissacaridose é uma doença rara, multissistêmica, progressiva e sem tratamento. Os objetivos deste estudo foram descrever os achados clínicos, radiográficos e anátomo-patológicos de um caso de mucopolissacaridose em um cão. Relata-se um caso de um cão, macho, Fox Paulistinha, de quatro meses de idade, oriundo de cruzamento com alto grau de endogamia. O cão apresentava apatia, dificuldades de locomoção, aumento de volume nas articulações, opacidade de córnea e dispneia inspiratória. Ao exame radiográfico observaram-se alterações bilaterais em linhas fiseais de vértebras, rádio e ulna, hepatomegalia e hipoplasia traqueal. Devido à acentuada dificuldade respiratória, o proprietário optou pela eutanásia. À necropsia, observou-se ausência das cartilagens da laringe, cricoide e aritenoide, coração globoso, e fígado e baço moderadamente aumentados. As alterações ósseas incluíram aumento do perímetro do crânio, má formação do esterno e costelas sinuosas. A histopatologia revelou displasia nas cartilagens da epiglote, da traqueia e articulares, nas quais os condrócitos apresentavam-se com citoplasma vacuolizado; havia ainda acentuado espessamento da íntima da aorta. O histórico de cruzamentos com alto grau de endogamia, associado aos achados clínicos, radiográficos e anátomo-patológicos confluem para o diagnóstico de mucopolissacaridose.

Palavras-chave: canino, disostose multiplex, enzimas lisossomais.

\begin{abstract}
Mucopolysaccharidosis is a rare, multisystemic, progressive disease that has no cure. The objectives of this study were to describe the clinical, radiographic and anatomical and pathological findings of a case of mucopolysaccharidosis in a dog. It reports the case of a male dog of the Fox Paulistinha (Brazilian Terrier) breed, four months of age, derived from cross-breeding with high degree of endogamy. The animal exhibited apathy, walking difficulty, enlarged joints, opacity of the cornea, and inspiratory dyspnea. On X-ray, bilateral changes were observed in the physeal lines of vertebrae, radius and ulna, as well as enlarged liver and tracheal hypoplasia. Due to the accentuated respiratory difficulty, the owner decided to euthanize the dog. Necropsy showed the absence of the larynx, cricoid and arytenoid cartilages, a distended heart, and moderately enlarged liver and spleen. Bone changes included increased cranial perimeter, malformation of the sternum, and twisted ribs. Histopathology revealed dysplasia in the cartilage of the epiglottis, trachea and joints, in which the chondrocytes presented with vacuolated cytoplasm; there was also accentuated thickening of the aortic intima. The history of cross-breeding with a high degree of endogamy, associated with the clinical, radiographic and anatomical and pathological findings, converged to a diagnosis of mucopolysaccharidosis.
\end{abstract}

Keywords: canine, dysostosis multiplex, lysosomal enzymes.

\section{Introdução}

Mucopolissacaridose (MPS) pertence a um grupo de doenças congênitas, geradas por deficiência de enzimas lisossomais específicas, que catalizam a degradação dos glicosaminoglicanos (GAGs), geralmente presentes no tecido conjuntivo, e geram, dessa forma, acúmulo lisossomal,
Como citar: Veiga, C. C. P., Oliveira, L. I., Silva, R. S., Oliveira, M. C., Daoualibi, Y., Deleutério, E. O., Alonso, L. S., \& Brito, M. F. (2017). Mucopolissacaridose em um cão: relato de caso Brazilian Journal of Veterinary Medicine, 39(4), 284-291. doi: 10.29374/2527-2179.bjvm018417

Fonte de financiamento: CAPES

Conflito de interesses: Os autores declaram não haver conflito de interesses que precisam ser informados.

Recebido: Julho 23, 2017.

Aceito: Agosto 01, 2017.

O estudo foi realizado na Universidade Federal Rural do Rio de Janeiro - UFRRJ, Seropédica, RJ, Brasil.

\section{*Correspondência}

Marilene de Farias Brito

Instituto de Veterinária, Universidade Federal Rural do Rio de Janeiro - UFRRJ

Rodovia BR 465, Km 7, Antiga Estrada Rio-São

Paulo, Anexo I do Instituto de Veterinária CEP 23891-000 - Seropédica (RJ), Brasil E-mail:marilene@ufrrj.br 
que culmina com disfunção de células, tecidos ou órgãos (Torres et al., 1997; Wang et al., 2011; Coutinho et al., 2012).

Existem quatro vias diferentes de degradação lisossomal dos GAGs, que são caracterizadas pelo tipo de molécula do GAG que será degradada: sulfato dermatan, sulfato heparan, sulfato queratan e sulfato condroitan (Coutinho et al., 2012).

A MPS éuma doença rara, e os sinais clínicos variam de acordo com a localização do acúmulo e com a enzima que está deficiente, mas usualmenteé multissistêmica, progressiva e sem tratamento (Giugliani et al., 2010; Wang et al., 2011). Os sinais clínicos são caracterizados por comprometimento das vias respiratórias, perda auditiva, displasia cardíaca valvular, estenose coronária, retardo mental, aumento dos órgãos devido ao aumento das células causado pelo acúmulo de GAGs, opacificação corneana, defeitos esqueléticos, compressão da medula espinhal e restrição da mobilidade articular (Torres et al., 1997; Wang et al., 2011; Coutinho et al., 2012). As alterações esqueléticas associadas à doença recebem a denominação genérica de disostose multiplex, que reúne um conjunto de anormalidades em todo o esqueleto, e são sugestivas de doenças do armazenamento de mucopolissacarídeos e glicoproteína (Simonaro et al., 1999).

Em animais, esta síndrome já foi relatada em cães (Haskins et al., 1984; Dombrowski et al., 2004; Arias et al., 2011), gatos (Gitzelmann et al., 1994; Wang et al., 2015) e camundongos (Birkenmeier et al., 1989).

As alterações radiográficas, achados anátomo-patológicos e níveis elevados de enzimas que degradam os glicosaminoglicanos na urina sugerem uma desordem do tipo MPS, mas não são consistentes, por si só, para o diagnóstico definitivo, o qual somente pode ser obtido através de testes no plasma que verifiquem qual a enzima está deficiente (Apte, 2009).

Os objetivos deste estudo foram descrever o quadro clínico, os achados radiográficos e de necropsia, exames histológicos e histoquímicos de um caso de mucopolissacaridose em um cão.

\section{Histórico}

Relata-se um caso de um cão, macho, Fox Paulistinha, de quatro meses deidade, oriundo de uma ninhada de cinco filhotes com cruzamento com alto grau de endogamia. O cão, diferentemente dos demais nascidos na mesma ninhada que eram ativos, apresentava acentuada apatia, retardo no crescimento, dificuldades de locomoção, aspecto corporal "atarracado" e também não emitia sons. Um funcionário da fazenda na qual a ninhada nasceu relatou que já ocorrera nascimento de cães com semelhantes problemas de locomoção em ninhadas anteriores. O cão foi encaminhado para o Setor de Clínica Médica de Pequenos Animais do Hospital Veterinário da Universidade Federal Rural do Rio de Janeiro (HVPA-UFRRJ). Ao exame físico observou-se aumento de volume nas articulações, dificuldade de locomoção, opacidade de córnea e dispneia inspiratória. Com o uso de um equipamento de Raio-X, modelo Cr125 - 300MA, da marca Intecal foram obtidas imagens radiográficas torácicas, abdominais e pélvicas nas projeções látero-lateral e ventro-dorsal, e dos membros apendiculares nas projeções médio-lateral e crânio-caudal, sem que houvesse necessidade de anestesia ou sedação prévia do paciente.

Ao exame radiográfico do cão, os corpos vertebrais se mostraram mais curtos; a linha fisária das vértebras lombares era irregular, com epífises pequenas, de superfície irregular e radioluscente. Algumas epífises e linhas fiseais estavam ausentes.

Nos membros torácicos, as linhas fiseais dos rádios e das ulnas eram irregulares e radioluscentes, e os núcleos de formação dos ossos do carpo apresentavam-se pequenos eirregulares, bem como as linhas fiseais dos metacarpos. As articulações coxofemorais estavam luxadas crânio-dorsalmente e o acetábulo apresentavam-se raso, com linhas fiseais largas, radioluscentes e irregulares, bem como as linhas fiseais dos platôs tibiais.

Em decúbito lateral, foi possível a melhor observação dos bordos hepáticos que ultrapassavam o gradil costal, o que caracterizou hepatomegalia. O trajeto traqueal estava preservado e o lúmen reduzido por um processo hipoplásico da traqueia.

O cão apresentou acentuada dificuldade respiratória e o proprietário optou pela eutanásia. O animal foi encaminhado para o Setor de Anatomia Patológica da Universidade Federal Rural do Rio de Janeiro (UFRRJ) (Figura 1). À necropsia, observou-se opacidade bilateral das córneas (Figura 2). A cavidade oral exibia língua de tamanho aumentado (desproporcional à idade) e borda da gengiva era avermelhada junto ao sulco gengival (no contorno dos dentes), ainda foi vista uma 


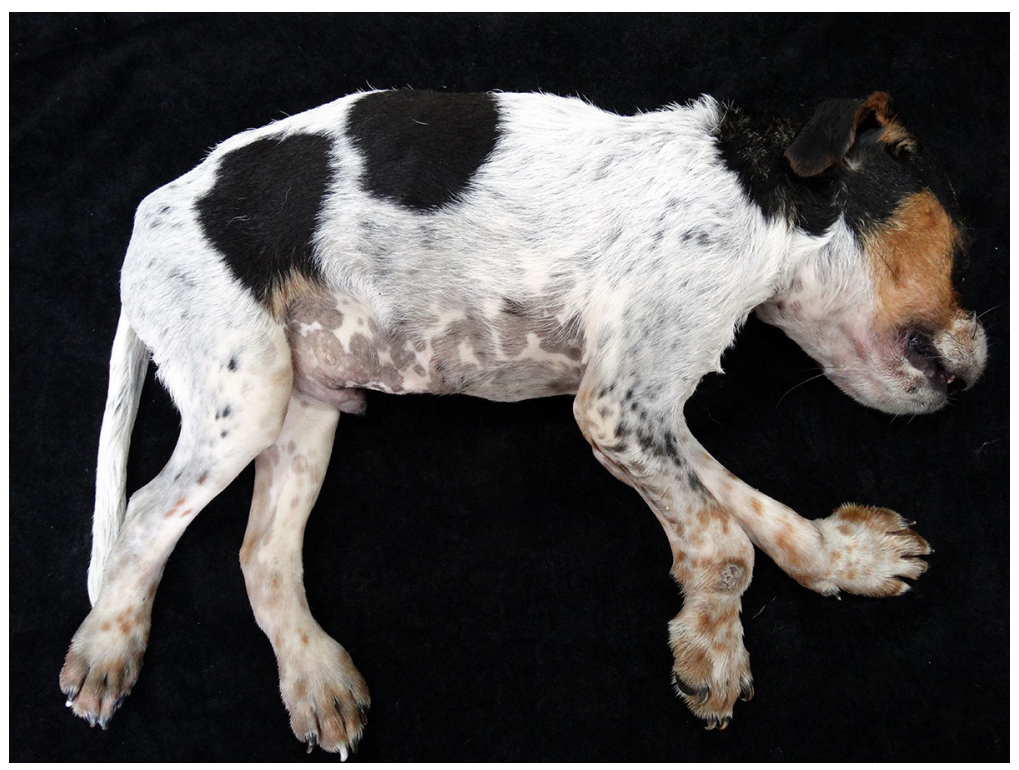

Figura 1. Observa-se acentuada deformidade esquelética, na qual os membros se encontram encurvados, principalmente os membros torácicos.

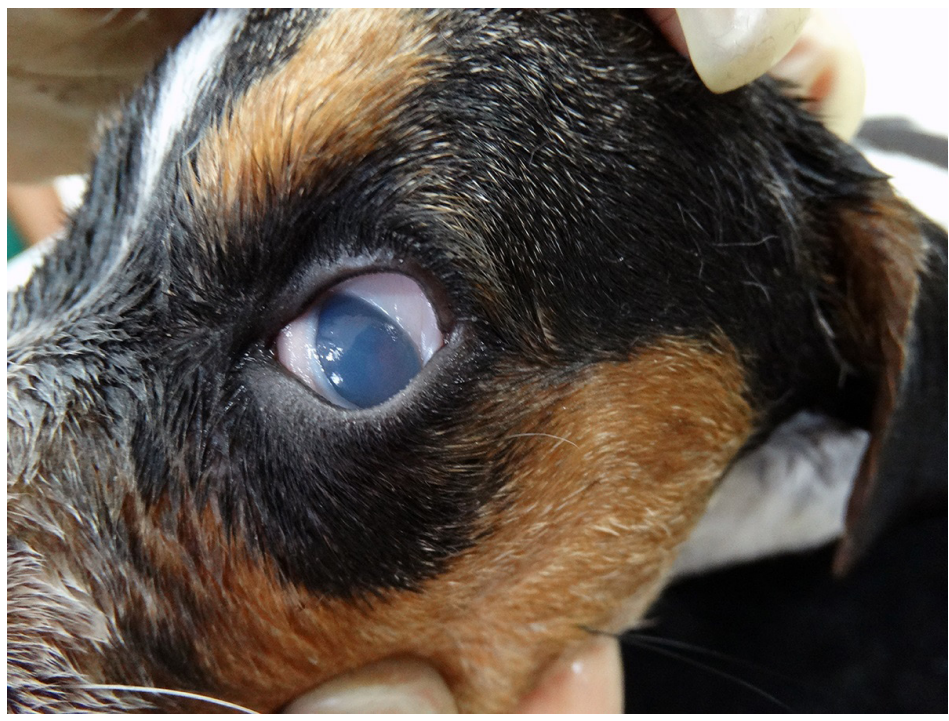

Figura 2. Olho esquerdo com opacidade de córnea.

úlcera na face ventral da língua, próximo ao freio lingual. Verificou-se excessiva mobilidade dos dentes incisivos superiores e inferiores, e mobilidade moderada de dentes caninos. A pele e o tecido subcutâneo apresentavam pelos relativamente longos (hirsutismo) e o panículo adiposo subcutâneo era escasso. Os linfonodos mandibulares estavam moderamente aumentados, esbranquiçados e úmidos ao corte.

Observou-se ausência das cartilagens cricoide e aritenoide da laringe e a epiglote apresentava-se aparentemente normal. As pregas vocais encontravam-se rudimentares e os vestíbulos laterais da laringe eram rasos. À abertura da cavidade torácica, os pulmões estavam difusamente vermelho escuros e com moderado edema ao corte. O coração era globoso, com epicárdio espessado e com áreas multifocais esbranquiçadas.

À abertura da cavidade abdominal, o fígado estava moderadamente aumentado, e ocupava mais da metade da cavidade abdominal. O baço apresentava-se moderadamente aumentado, com bordas arredondadas e face dorsal liso. Os rins exibiam áreas avermelhadas, circunscritas, na 
superfície capsular. O estômago tinha a mucosa levemente espessada por edema. Os segmentos do intestino delgado apresentavam moderada quantidade de muco misturado à bile.

Alterações ósseas incluíram aumento do perímetro do crânio em relação ao corpo. Havia deformidades esqueléticas nos quatro membros, tais como membros torácicos encurvados (Figura3), e havia substância mucoide no tecido subcutâneo sobre as articulações das falanges. Havia ainda, má formação do esterno, o manúbrio era globoso com 1,5 cm de espessura. As costelas eram sinuosas, excessivamente encurvadas, delgadas e frágeis (Figura 4). Na cabeça do fêmur a superfície era irregular e havia uma fossa côncava com ausência de cartilagem. Havia acentuada atrofia dos músculos intercostais.

As articulações apresentavam cápsulas articulares dos membros posteriores amplas, espessadas eirregulares. As articulações metacarpofalangeanas estavam espessadas, tortuosas, com a cavidade aumentada e com deformidade angular do tipo valgo. O líquido sinovial exibia aspecto gelatinoso.

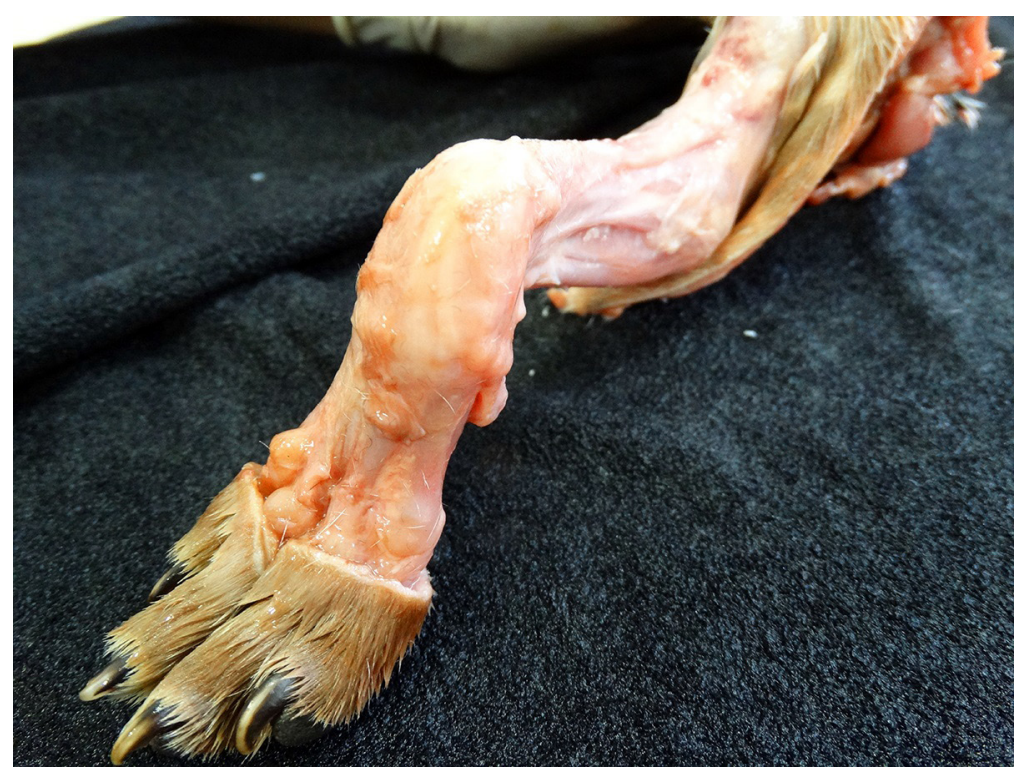

Figura 3. Membro torácico direito dissecado, evidenciando acentuada deformidade de estruturas esqueléticas e ligamentares.

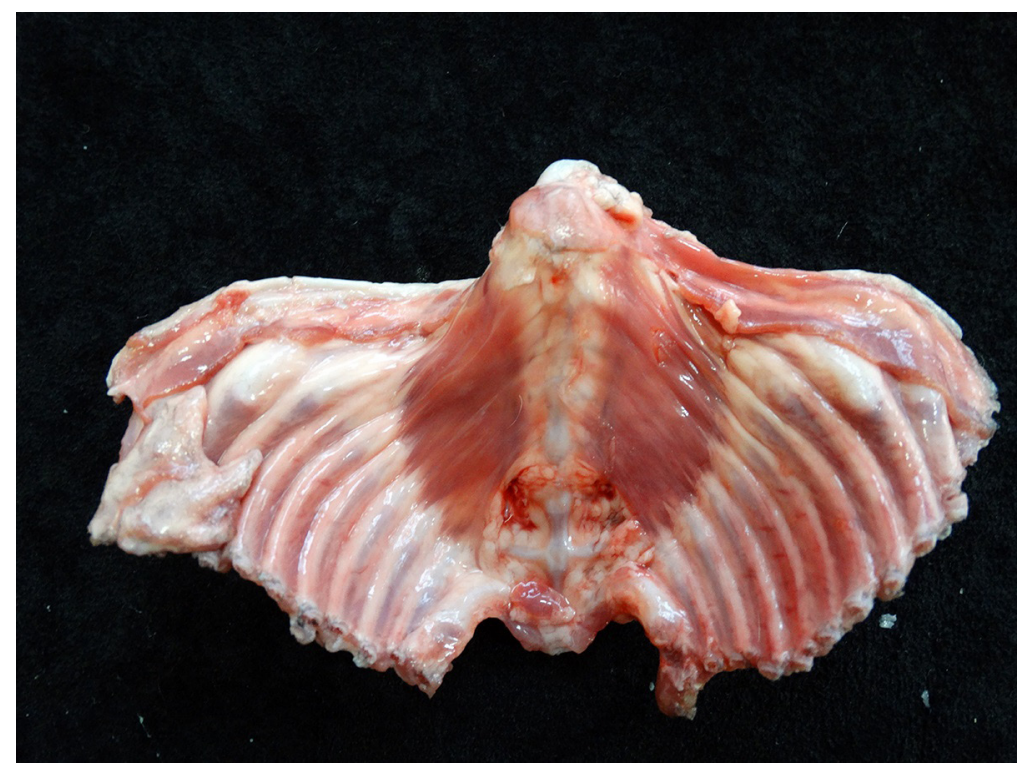

Figura 4. Má formação do esterno; costelas sinuosas e excessivamente encurvadas e delgadas. 
Fragmentos de diversos órgãos foram colhidos, fixados em formol a 10\% tamponado, e processados de acordo com a técnica histológica de rotina. A histopatologia revelou cartilagem da laringe (epiglote) com a lâmina própria edemaciada e com infiltrado inflamatório linfo-plasmocitário, focalmente extensivo, acentuado; ambas as cartilagens, hialina e elástica, encontravam-se desorganizadas e com superfície irregular. No pericôndrio havia alguns macrófagos. Na cartilagem, os condrócitos exibiam citoplasma evidente, eosinofílico e vacuolizado, e núcleo picnótico. A matriz interterritorial apresentava basofilia aumentada e focos de descontinuidade do tecido cartilaginoso, com infiltração de macrófagos, plasmócitos e material basofílico, o que conferia um aspecto displásico.

A traqueia apresentava a cartilagem do anel traqueal com superfície irregular e grande espaço entre esta superfície e o tecido conjuntivo fibroso da submucosa, onde se encontravam células soltas e com o citoplasma escasso (Figura 5). A aorta apresentava a túnica média aproximadamente três vezes mais espessa pela grande quantidade de tecido fibroso presente; ora havia moderado espaçamento das fibras e lâminas elásticas da túnica média, ora foram vistas células "claras" nas três túnicas (Figura 6). As cápsulas articulares das articulações afetadas apresentavam a superfície cartilaginosa irregular, com infiltração por macrófagos associados a raros linfócitos, com material anfofílico, finamente granular em seu citoplasma e no interstício, positivas nas colorações de ácido periódico de Schiff (PAS) e alcian blue. No pericôndrio havia células de formato cúbico a fusiforme, com grande relação núcleo:citoplasma (fibroblastos), focos de descontinuidade do tecido cartilaginoso, delimitados por uma forte coloração eosinofílica no PAS (muco concentrado) e infiltração por linfócitos e principalmente por macrófagos, e material basofílico, positivos no alcian blue e PAS. Os condrócitos dos tecidos cartilaginosos revelaram citoplasma com diversos vacúolos (aspecto de células "claras") visualizados no HE e Alcian blue.

Os pulmões revelavam acentuado edema intra-alveolar, pequenos focos de enfisema e acentuados macrófagos alveolares ativados, compostos por citoplasma vacuolizado que se coraram no PAS. Havia, em alguns vasos sanguíneos, tecido conjuntivo frouxo vacuolizado (edema). Os condrócitos da cartilagem bronquial tinham citoplasma eosinofílico e vacuolizado, além de núcleos picnóticos. Nos demais órgãos mencionados não havia alterações histológicas significativas.

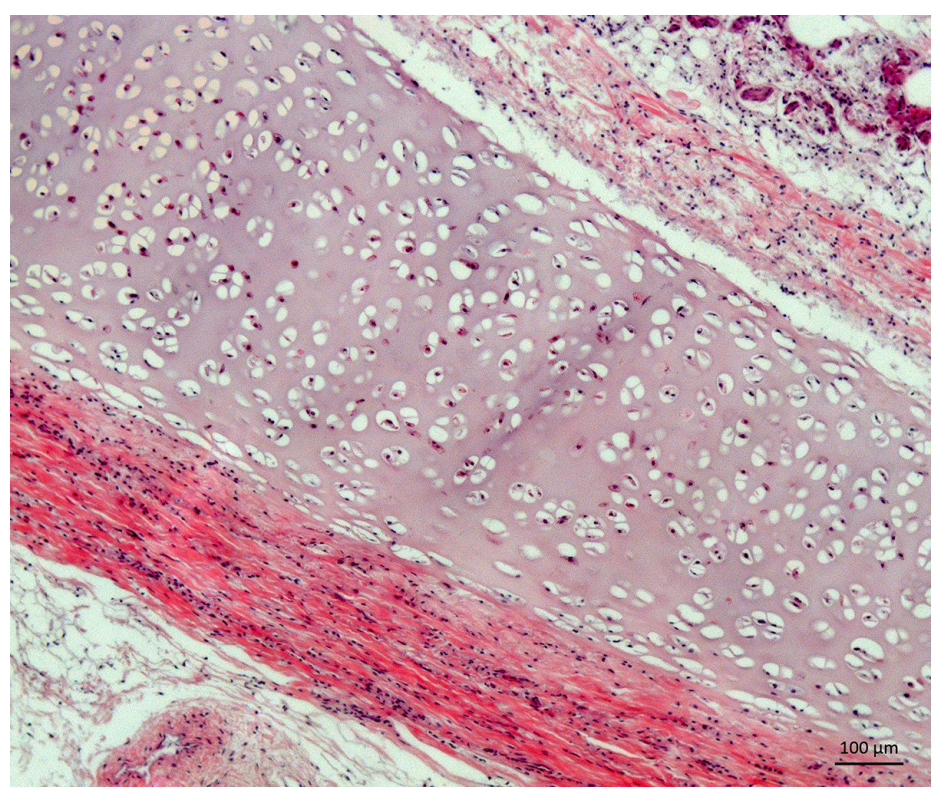

Figura 5. Cartilagem do anel traqueal com disposição irregular dos condrócitos (displasia) e aumento do espaço entre a cartilagem e o tecido conjuntivo fibroso da submucosa, HE, obj.10. 


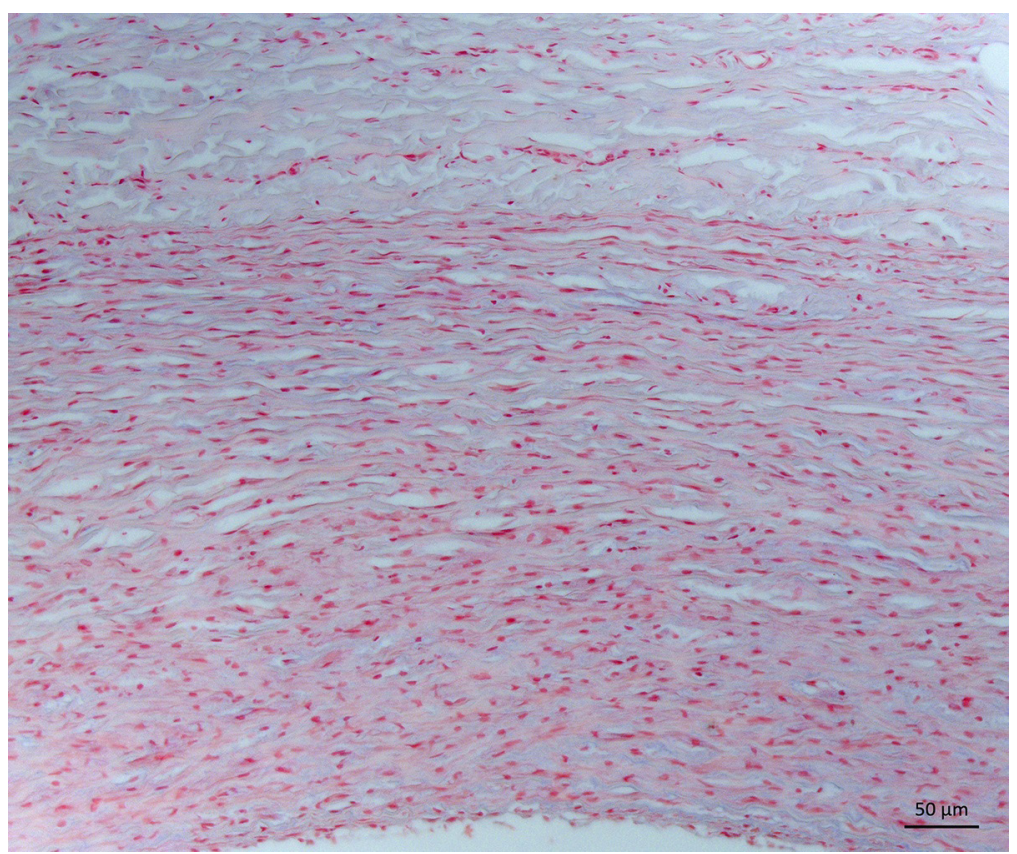

Figura 6. Artéria aorta com acentuado espessamento da túnica média pela grande quantidade de tecido fibroso, e aumento do espaçamento entre as fibras elásticas, Alcian blue, obj.2O.

\section{Discussão}

O diagnóstico de mucopolissacaridose no canino deste estudo baseou-se nos achados clínicos, exames radiográficos e anatômicos, bem como nos exames de histopatologia e histoquímica.

Desordens lisossomais de glicosaminoglicanos interrompem a função normal dos tecidos e, em animais, os sinais clínicos são semelhantes aos relatados em humanos. Os sinais clínicos incluem má formação de ossos e cartilagens, retardo mental, opacidade da córnea, e aumento de órgãos abdominais (Neufeld \& Muenzer, 1995), sinais clínicos também observados no cão do presente caso.

No Brasil, a mucopolissacaridose foi relatada em dois cães. O primeiro era um macho, Pitbull, de 60 dias, com dificuldade de locomoção, aumento de volume e deformidades em articulações e pectus cavinatum; e o segundo era uma fêmea, Rottweiler, de oito meses, com dificuldade progressiva de locomoção, tetraplegia, opacidade da córnea, aumento de volume na língua e deformidade no crânio (Arias et al., 2011), o que também foi encontrado no caso do nosso estudo.

Neste estudo, o cão apresentava dismorfismos osteoarticulares, bem como hepatomegalia e hipoplasia traqueal, similar ao que se descrevem em outros casos da doença. As alterações radiográficas incluem um conjunto de alterações esqueléticas, conhecidas por disostose multiplex, na qual os ossos são mais curtos, há erosão articular focal, efusão articular, subluxação de cotovelos e erosões nas epífises de todos os corpos vertebrais (Arias et al., 2011), má formação das cabeças umerais e suas respectivas cavidades glenoides, além de deformidades nos arcos costais, hepatomegalia, hipoplasia traqueal (Schultheiss et al., 2000; Dombrowski et al., 2004; Hytönen et al., 2012; Pérez et al., 2015).

As alterações cardiovasculares nessa síndrome levam ao acúmulo de MPS no miocárdio, válvulas cardíacas e grandes vasos. O miocárdio geralmente sofre hipertrofia, as válvulas cardíacas ficam espessadas e levam ao regurgitamento ou estenose, assim como, surgem alterações de grandes vasos, na qual a aorta apresenta a túnica íntima acentuadamente espessada e por vezes são vistas células "claras" nas três túnicas, à histopatologia (Wang et al., 2011; Braunlin et al., 2006). No presente estudo notou-se o espessamento acentuado da túnica íntima e presença de aspecto de células "claras" da aorta, que corresponde a células vacuolizadas.

Além das alterações no sistema cardiovascular, histologicamente observam-se numerosos vacúolos citoplasmáticos em diversos órgãos, inclusive em condrócitos das placas de crescimento 
vertebral (Dombrowski et al., 2004). Neste caso, os condrócitos revelaram citoplasma com diversos vacúolos (aspecto de células "claras") visualizados nas colorações de PAS e alcian blue.

Hytönen et al. (2012), estudaram os defeitos esqueléticos encontrados em cães da raça Fox Paulistinha (Terriers Brasileiros), e uma mutação no gene GUSB foi identificado. O cão do presente estudo era desta mesma raça, porém não foram feitos testes genéticos.

O diagnóstico diferencial para os animais que apresentam um catabolismo anormal de mucopolissacaridose éimportante, uma vez que as alterações radiográficas podem ser semelhantes às descritas em outras afecções relacionadas às anormalidades de crescimento em filhotes. No hipotireoidismo congênito, por exemplo, o cão apresenta tamanho corpóreo desproporcional, cabeça grande e larga, língua protraída e espessa, e membros encurtados (Catharine et al., 2004; Pérez et al., 2015). As causas relatadas incluem deficiência de iodo, disgenesia tireoidea e disormonogênese (Scott-Moncrieff \& Guptill-Yoran, 2005). A hipótese de hipotireoidismo congênito nessa ninhada não se sustenta, pois evidências de prováveis causas não foram constatadas nesse caso, e, em função dos demais achados de necropsia e da histopatologia, bem como em face do histórico relatado, típico de doença genética que envolve alto grau de endogamia, confirmou-se o diagnóstico.

\section{Conclusões}

O diagnóstico do presente relato, baseado nos achados clínicos, exames radiográficos, anatômicos, histopatológicos e histoquímicos, associados ao histórico de ninhadas com cruzamento de alto grau de endogamia, é característico de mucopolissacaridose.

\section{Referências}

Apte, B. N. A. (2009). Simple and rapid method for the diagnosis of mucopolysaccharidoses (Mps). Journal of Clinical and Diagnostic Research, 3, 1488-1492.

Arias, M. V. B., Marcasso, R. A., Raskin, S., Bego, S. C., \& Burin, M. G. (2011). Mucopolissacaridose em cão: relato de dois casos. Ars Veterinária, 27, 226-230.

Birkenmeier, E. H., Davisson, M. T., Beamer, W. G., Ganschow, R. E., Vogler, C. A., Gwynn, B., Lyford, K. A., Maltais, L. M., \& Wawrzyniak, C. J. (1989). Murine mucopolysaccharidosis type VII: characterization of a mouse with beta-glucuronidase deficiency. The Journal of Clinical Investigation, 83(4), 1258-1266. http://dx.doi.org/10.1172/ JCl114010. PMid:2495302.

Braunlin, E. A., Berry, K. I., \& Whitley, C. B. (2006). Cardiac findings after enzyme replacement therapy for mucopolysaccharidosis type I. The American Journal of Cardiology, 98(3), 416-418. http://dx.doi.org/10.1016/j. amjcard.2006.02.047. PMid:16860035.

Catharine, R. J., Scott, M., \& Yoran, L. G. (2004). Hipotireoidismo. In S. J. Ettinger \& E. C. Feldman (Eds.), Tratado de medicina interna (5. ed., pp. 1497-1504). Rio de Janeiro: Guanabara Koogan.

Coutinho, M. F., Lacerda, L., \& Alves, S. (2012). Glycosaminoglycan storage disorders: a review. Biochemistry Research International, 2012, 471325. http://dx.doi.org/10.1155/2012/471325. PMid:22013531.

Dombrowski, D. C. S., Carmichael, K. P., Wang, P., O'Malley, T. M., Haskins, M. E., \& Giger, U. (2004). AVMA Mucopolysaccharidosis type VII in a German Shepherd Dog. Journal of the American Veterinary Medical Association, 224(4), 553-557. http://dx.doi.org/10.2460/javma.2004.224.553. PMid:14989549.

Gitzelmann, R., Bosshard, N. U., Superti-Furga, A., Spycher, M. A., Briner, J., Wiesmann, U., Lutz, H., \& Litschi, B. (1994). Feline mucopolysaccharidosis VII due to b-glucuronidase deficiency. Veterinary Pathology, 31(4), 435-443. http://dx.doi.org/10.1177/030098589403100405. PMid:7941232.

Giugliani, R., Federhen, A., Rojas, M. V., Vieira, T., Artigalás, O., Pinto, L. L., Azevedo, A. C., Acosta, A., Bonfim, C., Lourenço, C. M., Kim, C. A., Horovitz, D., Bonfim, D., Norato, D., Marinho, D., Palhares, D., Santos, E. S., Ribeiro, E., Valadares, E., Guarany, F., de Lucca, G. R., Pimentel, H., Souza, I. N., Correa, J., Fraga, J. C., Goes, J. E., Cabral, J. M., Simionato, J., Llerena Junior, J., Jardim, L., Giuliani, L., Silva, L. C., Santos, M. L., Moreira, M. A., Kerstenetzky, M., Ribeiro, M., Ruas, N., Barrios, P., Aranda, P., Honjo, R., Boy, R., Costa, R., Souza, C., Alcantara, F. F., Avilla, S. G., Fagondes, S., \& Martins, A. M. (2010). Mucopolysaccharidosis I, II, and VI: Brief review and guidelines for treatment. Genetics and Molecular Biology, 33(4), 589-604. http://dx.doi.org/10.1590/S141547572010005000093. PMid:21637564.

Haskins, M. E., Desnick, R. J., DiFerrante, N., Jezyk, P. F., \& Patterson, D. F. (1984). Beta-glucuronidase deficiency in a dog: a model of human mucopolysaccharidosis VII. Pediatric Research, 18(10), 980-984. PMid:6436780.

Hytönen, M. K., Arumilli, M., Lappalainen, A. K., Kallio, H., Snellman, M., Sainio, K., \& Lohi, H. (2012). A novel GUSB mutation in Brazilian terriers with severe skeletal abnormalities defines the disease as mucopolysaccharidosis VII. PLoS One, 7(7), e40281. http://dx.doi.org/10.1371/journal.pone.0040281. PMid:22815736. 
Neufeld, E. F., \& Muenzer, J. (1995). The mucopolysaccharidose. In C. R. Scriver, A. L. Beaudet, W. S. Sly, \& D. Valle (Eds.), The metabolic and molecular bases of inherited disease (7thed., pp. 2465-2495). New York: McGraw-Hill.

Pérez, M. L., Kridel, H. A., Gallagher, A., Sheppard, B. J., Reese, S., Kondo, H., Alleman, R., \& Giger, U. (2015). Mucopolysaccharidosis type VI in a juvenile miniature schnauzer dog with concurrent hypertriglyceridemia, necrotizing pancreatitis, and diabetic ketoacidosis. The Canadian Veterinary Journal. La Revue Veterinaire Canadienne, 56(3), 272-277. PMid:25750448.

Schultheiss, P. C., Gardner, S. A., Owens, J. M., Wenger, D. A., \& Thrall, M. A. (2000). Mucopolysaccharidosis VII in a cat. Veterinary Pathology, 37(5), 502-505. http://dx.doi.org/10.1354/vp.37-5-502. PMid:11055883.

Scott-Moncrieff, J. C. R., \& Guptill-Yoran, L. (2005). Hypothyroidism. In S. J. Ettinger \&, E. C. Feldman (Eds.), Textbook of veterinary internal medicine (6th ed., pp. 1535-1543). St Louis: Elsevier-Saunders.

Simonaro, C. M., Haskins, M. E., Abkowitz, J. L., Brooks, D. A., Hopwood, J. J., Zhang, J., \& Schuchman, E. H. (1999). Autologus transplantation of retrovirally transduced boné marrow or neonatal blood cells into cats can lead to long-term engraftment in the absence of myeloablation. Gene Therapy, 6(1), 107-113. http://dx.doi. org/10.1038/sj.gt.3300797. PMid:10341882.

Torres, L. F. B., Noronha, L., Jacob, G. V. V., \& Antoniuk, S. (1997). Achados anatomo-patológicos e ultraestruturais na mucopolissacaridose. Arquivo Neuro-psiquiatria., 55(1), 114-121. http://dx.doi.org/10.1590/s0004-282X1997000100018.

Wang, P., Sorenson, J., Strickland, S., Mingus, C., Haskins, M. E., \& Giger, U. (2015). Mucopolysaccharidosis VII in a cat caused by 2 adjacent missense mutations in the GUSB Gene P. Journal of Veterinary Internal Medicine, 29(4), 1022-1028. http://dx.doi.org/10.1111/jvim.13569. PMid:26118695.

Wang, R. Y., Covault, K. K., Halcrow, E. M., Gardner, A. J., Cao, X., Newcomb, R. L., Dauben, R. D., \& Chang, A. C. (2011). Carotid intima-media thickness is increased in patients with mucopolysaccharidoses. Molecular Genetics and Metabolism, 104(4), 592-596. http://dx.doi.org/10.1016/j.ymgme.2011.09.004. PMid:21963080. 